
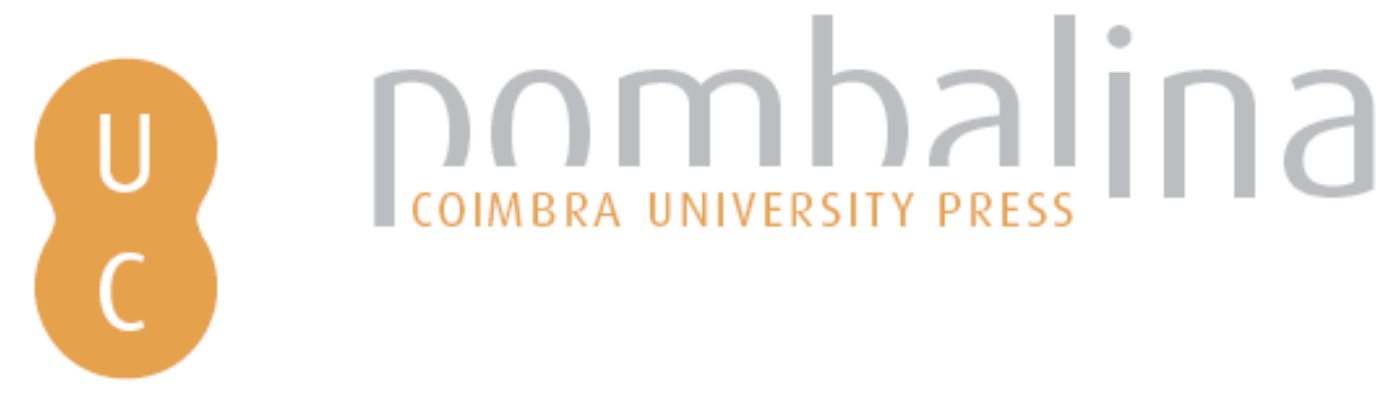

\title{
A linguagem do mito e a sua força de interpelação: Antígona frente a los jueces, de Andrés Pociña
}

Autor(es): $\quad$ Fialho, Maria do Céu

Publicado por: Imprensa da Universidade de Coimbra

URL

persistente: URI:http://hdl.handle.net/10316.2/40004

DOI: DOI:https://doi.org/10.14195/978-989-26-1115-0_12

Accessed : $\quad$ 26-Apr-2023 12:44:42

A navegação consulta e descarregamento dos títulos inseridos nas Bibliotecas Digitais UC Digitalis, UC Pombalina e UC Impactum, pressupõem a aceitação plena e sem reservas dos Termos e Condições de Uso destas Bibliotecas Digitais, disponíveis em https://digitalis.uc.pt/pt-pt/termos.

Conforme exposto nos referidos Termos e Condições de Uso, o descarregamento de títulos de acesso restrito requer uma licença válida de autorização devendo o utilizador aceder ao(s) documento(s) a partir de um endereço de IP da instituição detentora da supramencionada licença.

Ao utilizador é apenas permitido o descarregamento para uso pessoal, pelo que o emprego do(s) título(s) descarregado(s) para outro fim, designadamente comercial, carece de autorização do respetivo autor ou editor da obra.

Na medida em que todas as obras da UC Digitalis se encontram protegidas pelo Código do Direito de Autor e Direitos Conexos e demais legislação aplicável, toda a cópia, parcial ou total, deste documento, nos casos em que é legalmente admitida, deverá conter ou fazer-se acompanhar por este aviso.

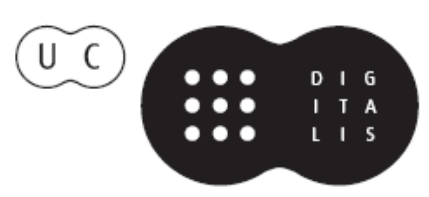




\section{JOÃO CORRÊA-CARDOSO MARIA DO CÉU FIALHO}

(Coordenadores)

\section{A LINGUAGEM NA PÓLIS}

IMPRENSA DA UNIVERSIDADE DE COIMBRA COIMBRA UNIVERSITY PRESS
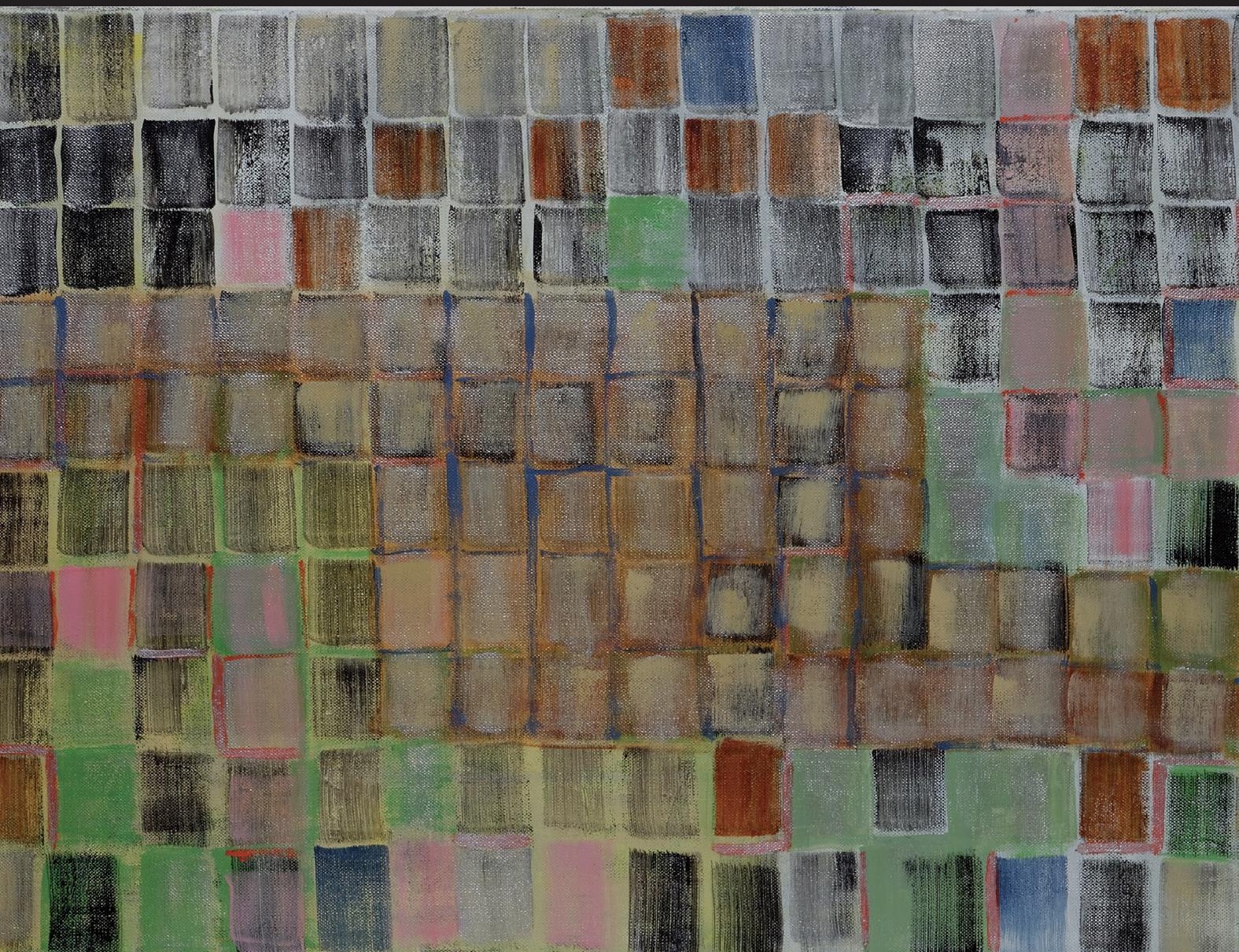


\title{
A Linguagem DO Mito E A SUA FORÇA \\ DE INTERPELAÇÃO: ANTÍGONA FRENTE A LOS JUECES, DE ANDRÉS POCIÑA
}

\author{
THE LANGUAGE OF MYTH AND ITS \\ I NTERPELLATION POWER: \\ ANDRÉS POCIÑA'S ANTÍGONA FRENTE \\ A LOS JUECES
}

\author{
Maria do Céu Fialho \\ Universidade de Coimbra/CECH \\ mcfialhofluc@gmail.com
}

\begin{abstract}
Resumo: Esta reescrita de Antígona inscreve-se numa trilogia de voz feminina. A acção decorre no tribunal que julga Antígona, já depois da sua infracção. Creonte é apenas o tirano injusto e Antígona a voz da justiça e do afecto, que reabilita Édipo, Jocasta, Polinices. Antígona liberta outras vozes femininas no tribunal, de modo a que Creonte seja posto em causa. O conflito entre ambos é inultrapassável e assim permanecerá no tribunal da História.
\end{abstract}

Palavras-chave: Antígona, Creonte, voz feminina, tribunal, reescrita do mito.

\begin{abstract}
This rewriting of Antigone is integrated in a trilogy of female voice. The action takes place in a court of law where Antigone is on trial after her infraction to Creon's edict. Creon is nothing but the injust tyrant and Antigone is the voice of justice and love, that rehabilitates Oedipus, Jocasta, Polynices. Antigone liberates other female voices in the court, so
\end{abstract}


that Creon's position is thrown in question. The conflict between both is unsurpassable and so it will remain on the History trial.

Key words: Antigone, Creon, female voice, trial, rewriting myth.

O espaço de identidade que nós partilhamos com a Cultura Grega Antiga, e que se torna ponte e viabiliza a sua compreensão, não deve ser tomado como identidade absoluta, mas como um ponto de partida para a percepção enriquecedora da diferença entre ambos os mundos - diferença sentida, na cultura grega, como um manancial de 'novo' ou de 'esquecido', a recuperar criticamente. Assim se opera o alargamento daí decorrente dos nossos próprios horizontes.

É neste contexto que o mito de Antígona e a Antígona a que a leitura criadora de Sófocles deu genial forma e expressão, devem ser consideradas. Acresce, quanto ao mito e quanto à tragédia sofocliana, um outro factor que há que ter em consideração, decorrente, obviamente, da própria natureza do mito e da obra de arte: ambos escapam a uma compreensão que os esgote. Quanto à tragédia, nem a compreensão do público a que se destinava foi, por certo, unívoca. De resto, como obra aberta, ela transporá a sua historicidade para uma universalidade carregada de futuro onde o seu sentido se manterá plurívoco e inesgotável. É, de resto, esta, a verdadeira dimensão do 'clássico'. Antígona/Antígona recrear-se-ão em cada leitura, em cada representação.

Daqui decorre um corolário a ter necessariamente em conta nos estudos sobre tragédia grega: a nossa própria leitura interpretativa, porque historicamente situada, está também ela, a priori, marcada pela própria história de interpretação e de recepção da peça - tão rica e tão adequada a prestar-se como espaço de projecção de mundividências e interrogações e conflitos de cada época, na história da Europa. Há, pois, que tomar consciência deste processo e considerar 
até que ponto por ele estamos determinados, a fim de que ele se não interponha de forma fatal entre nós e a tragédia de Sófocles.

No que diz respeito à releitura criadora, a todo o processo de reescrita, Antígona é, simultaneamente, livre e determinada: livre, na medida em que o autor da recriação, se se trata de um genuíno e talentoso artista, goza daquela liberdade infraccionária e quase-demiúrgica própria da própria criação artística, ainda que se trate de um processo de reescrita; determinada, na medida em que o autor tem de respeitar o núcleo essencial do mito, ainda que seja sob a forma de referência de que, declaradamente, se distancia. A determinação decorre ainda de um factor comum ao estudioso: a historicidade do artista, cuja linguagem cultural e percepção primeiras se formaram na tradição da transmissão de leituras da obra (e. g.: Antígona como a expressão de um conflito inultrapassável de duas forças equivalentes, Antígona-mártir, Antígona heroína de todas as resistências, Antígona movida por um destino que tem de cumprir) ${ }^{1}$.

Lembrando a posição recorrente de Hannah Arendt, de que todos nós nascemos no passado, aprendemos a linguagem do passado, ainda que seja para a pôr em causa ${ }^{2}$, compreendemos que a reescrita criadora parte da aprendizagem dessa linguagem (e nela se inclui a obra e as suas leituras) para a transgredir, usando-a, por um processo de transposição, análogo ao da metáfora, para veicular novos significados, articular novas mensagens, explorar um universo de experiências e tensões políticas, existenciais, que encontram na narrativa-representação do mito de Antígona, eterno e renovado, a expressão adequada, a força da interpelação à comunidade a que se dirige.

\footnotetext{
${ }^{1}$ Fialho (2000) 29 sqq.

2 Posição de fundo em Entre o passado e o futuro (trad. do inglês 2006), Lisboa, Relógio de Água.
} 
Andrés Pociña, o conhecido catedrático de Literatura Latina da Universidade de Granada, surpreende-nos com uma poderosa Medeia de matriz greco-galega que domina o espaço cénico - o lugar de Camariñas, na Galiza, onde se refugia - com um monólogo em que se cruzam, incandescentes e contidos, como no interior de um vulcão, memórias e sentimentos. Os silêncios são os silêncios da própria paixão, traduzida na linguagem cultural galega. O texto dramático surge a partir de uma série de curtas narrativas escritas pelo autor e publicadas em 1977, com o título Se de desmiticar falades ${ }^{3}$

Coube a Juli Leal a encenação da peça, que teve a estreia em 25 de Maio de 2005 em Valência ${ }^{4}$. Desde então, a peça foi representada frequentes vezes, e com notável êxito, quer em Espanha quer em outros países, foi traduzida para várias línguas e tem sido objecto de estudos académicos.

Segue-se-lhe Atardecer en Mitilene, peça intimista, cujo círculo de acção é o círculo de Safo e das suas discípulas no jardim da mestra, em que, numa polifonia discreta, do espaço feminino, se cruzam e confrontam paixões que despertam, que anseiam por correspondência, paixões juvenis, em contraste com a maturidade passional contida da mestra 5 . A peça foi estreada em Granada em 2010, representada continuamente, em espaços diversos, até ao presente. $\mathrm{O}$ mesmo grupo teatral que a estreou - Grupo Afrodita, do I.E.S Bueno Crespo, de Granada - deslocou-se em Junho de 2011 ao pátio do Museu Nacional Machado de Castro, em Coimbra, onde representou a peça, no âmbito do XIII Festival de Teatro de Tema Clássico ${ }^{6}$.

\footnotetext{
3 Como refere Martínez Martínez (2009) 75-76, estas narrativas foram submetidas a uma profunda remodelação e deram, assim, origem à peça-monólogo representada em 2005.

${ }^{4}$ Vide Martínez Martínez, op. cit.75; 83-84, trata-se de uma produção do Grup de Recerca i Acció Teatral de la Universidad de Valéncia. Medeia foi representada com o maior êxito pela actriz Begoña Sáchez.

5 Romero Mariscal (2012) 203-217.

6 Brandão (2011) 842-843.
} 
Em Junho de 2015 Andrés Pociña supreende-nos de novo, ao editar, conjuntamente com as duas peças já conhecidas, representadas e traduzidas, uma peça inédita: uma Antígona frente a los jueces. O volume dá pelo título de Medea, Safo, Antígona (Tres piezas dramáticas), e foi publicado em Granada, Esdrújula Ediciones. O leitor percebe, à partida, que está perante uma Antígona que, simultaneamente, difere e depende das interpretações e reescritas de Antígona através dos tempos. Reconhece-se a rebeldia da protagonista, que infringe a proibição de sepultura de Polinices e que, em nome de um dever sagrado the presta honras fúnebres, bem como a prepotência de Creonte, prestes a punir a jovem, sob a capa do aparelho institucional. Da irredutibilidade destas duas figuras permanece o eco para além do desfecho da peça.

No entanto, a peça abre post factum, diversamente da sofocliana - a jovem já havia desobedecido, saído do palácio e prestado as honras fúnebres que lhe foram possíveis a Polinices. O espaço cénico-dramático é o de um tribunal que se prepara para a julgar, presidido por Creonte e constituído, com respeito pelas quotas de género, por dois juízes e duas juízas. A peça consiste nesse julgamento.

Sumamente importantes são as indicações cénicas do autor: a liberdade de disposição em cena é total, o guarda-roupa também o é, o ambiente é o da Hélade original, sem deixar de conter ecos de tempos futuros. O Coro perde a sua identidade coral homogénea, para passar a ser constituído por quatro elementos, singulares, de perfil diversificado, dos quais três assistem ao julgamento (Pueblo Uno, secretário do tribunal, Pueblo Dos, Pueblo Tres, Pueblo Cuatro, com a particularidade de se tartar de uma mulher velha, franzina e enérgica), podendo compreender um quinto elemento (Pueblo Quinto), sentado entre o público - isto é, o tempo/lugar do julgamento de Antígona amplifica-se e passa a compreender todo o espaço do espectáculo, palco e bancadas do público. Dir-se-ia que esta é uma táctica dramática antipódica do estranhamento brechtia- 
no, em função de uma mesma estratégia: desmontar a ficcionalidade do representado, para nele envolver criticamente o público como coisa sua, da sua história e do seu tempo, ainda que faça de conta que o espaço/tempo é o de Tebas. Em boa verdade, o julgamento de Antígona configura toda a leitura, interpretação, compreensão e decorrente reescrita do mito de uma Antígona de todas as épocas. A confirmá-lo estão as indicações cenográficas do autor, como a inicial, de apresentação da protagonista (p. 98):

Antígona, mujer joven, como fue siempre

O julgamento inicia-se com a intervenção do secretário (Pueblo Uno), para fazer o ponto da situação judicial: Antígona é acusada de crime, confirma-se que abdica de defensor, assumindo ela mesma a sua defesa. Do julgamento pode decorrer a absolvição, caso a ré seja inocentada, ou a prisão perpétua, já que, por iniciativa do rei defunto, Édipo, foi abolida a pena de morte - em reavaliação no preciso momento em que decorre este processo. O espectador é, assim, alertado para a diferença entre Édipo e Creonte, um tirano que reabriu a discussão sobre a pena de morte, bem como para o expectável enfrentamento retórico ético-político entre Antígona e os juízes, que constituirá a acção da peça7

O Juez Primero dita os autos judiciais. Antígona está parcialmente com eles: reconhece ser a autora das proibidas honras fúnebres a Polinices, seu irmão, mas refuta, reiteradamente, a culpa. Não reconhece culpa num gesto para o qual (p. 102):

...no hay ley, ni divina ni humana, que pueda castigarlo.

7 Quanto ao logos enquanto verdadeira acção de Antígona, tendente a ganhar peso nas reescritas mais modernas do mito, vide Honig (2013) 121-150. 
Formulada de outro modo, o leitor ou o público reconhece nestas palavras a certeza da Antígona sofocliana acerca dos princípios universais pelos quais havia regido os seus actos (Soph. Ant. 454-455):

...as leis não escritas e inabaláveis dos deuses.

Porém, aqui não é o recesso longínquo dos deuses a sede de tais princípios: a sua universalidade, a bem dizer, constitui uma utopia - eles seriam universais se todos os homens e mulheres fossem fiéis à dignidade e sentido de justiça e solidariedade que deveriam ser próprios da sua natureza humana, se escutassem a voz do seu íntimo e não construíssem barreiras à linguagem do coração, como se depreende de posterior argumentação da jovem, que opõe 'escrito' a 'inscrito' (p. 113):

...hay cosas que no están escritas en la leyes ni contempladas en las costumbres, pero se encuentran inscritas en el interior de nuestros corazones

É graças à intervenção do Pueblo Cuatro, a velha, franzina e enérgica, que Antígona logra concluir o seu primeiro discurso de defesa, várias vezes interrompido com o interrogatório do Juez Primero. Este elemento do povo mantém, de resto, esse seu papel de protesto enérgico e desafrontado, mesmo confrontando Creonte (e. g. p. 107):

Yo estoy aquí para lo que estoy. Sin voto, pero con voz, no se olvide.

A mesma velha arrasta os outros elementos do povo, no final, a reconhecer a razão da sua revolta, repetindo em coro - finalmente, em Coro - estas suas palavras (p. 120):

Demasiadas veces el pueblo calla cuando debería hablar! 
A sua adesão a Antígona sugere que esta mulher representa uma espécie de retrato antecipado de como seria Antígona, se tivesse envelhecido: nunca conformada com a injustiça e a tirania.

A competência retórica de Antígona e a certeza das suas razões leva-a a desmontar, sistematicamente, as acusações dos juízes, a ponto de fazer com que Creonte deixe cair a sua máscara de austera imparcialidade. E Antígona argumenta numa linguagem simples e fluida, por contraste com a formalidade da linguagem do tribunal. Ela refuta, sistematicamente, as acusações que partem do pressuposto das leis de Creonte. À luz dos princípios que invoca, inscritos no seu coração, não reconhece culpa alguma. Não há dogmas nem construções judiciais que prevaleçam como verdades, já que tudo depende do ponto de vista, da roupagem argumentativo, do traquejo político ou da límpida ligação à vida e vivência dos afectos e do dever deles decorrente (pp. 101-102):

No estoy de acuerdo en el modo que tiene el juez de presen$\operatorname{tar}$ los hechos. Sabe muy bien, porque para eso tiene estudios, y también mucha práctica política, que qualquier hecho puede ser interpretado de modos muy distintos según la manera de presentarlos. Por ejemplo, todas esas cosas que dijo, muy bien meditadas por cierto, y que además y alas traía dispuestas por escrito, yo puedo resumirlas en muchas menos palabras: yo enterré a Polinices porque era una persona, porque estaba muerto, porque era mi hermano. Ahí está la verdad complete, y eso no hay ley, ni divina ni humana, que pueda castigarlo.

Sem o tom provocatório de Antígona em Sófocles, que ousa chamar louco ao rei (v. 470), a Antígona de Andrés Pociña, com toda a naturalidade e num tom coloquial, desmonta as construções de Creonte, a quem não deixa de chamar 'tio' (p. 104): 
No deforme las cosas, tío. Yo jugaba más con Polinices, porque teníamos edades parecidas, por eso pore so quería menos a Eteocles.

Esta Antígona, na sua firmeza, é uma mulher de afectos, sem a dureza da homónima sofocliana. Se, na peça de Sófocles, Antígona proclama (v. 323) "nasci para amar, não para odiar”, não deixa de se contradizer, já no prólogo, quando Ismena se distancia dos seus planos, por receio, e tenta dissuadi-la de levar por diante o seu arrojado intento (v. 93): "se continuares a falar assim, seras objecto de ódio da minha parte”. Não é o que acontece na peça de Andrés Pociña, em que Antígona defende Ismena (também esta, como em Sófocles, se declara, a certa altura, falsamente conivente com Antígona), reconhecendo, com alguma ternura, que sua irmã mente por mero afecto (109):

Ismena miente. Miente ahora, por amor a mí, cuando me ve en peligro de ser condenada. Siempre fue así, una niña buena, pero sin energía, sin decision, siempre lenta cuando hay prisa.

O autor concebe, então, uma Antígona em que o princípio enunciado pela de Sófocles corresponde ao carácter da figura, no seu todo - não há ódio, mas o propósito de repor a justiça dos gestos, das relações, da correcta compreensão dessas mesmas relações familiares e da redenção dos mortos, cobertos pelo juízo de preconceito, que carregam com a sua memória a leitura que deles é feita por Creonte e por muitos séculos. Inspirado na relação e na referência fulcral que a Antígona sofocliana demonstra e reitera energicamente para com os seus mortos, de tal modo que o espectador percebe nela uma vontade de a eles se juntar, uma referência maior à morte que 
ao mundo dos vivos e da pólis ${ }^{8}$, Andrés Pociña reelabora livremente essa relação, demonstrando extrema originalidade.

Que estratégia utiliza o autor para reorganizar esta parte do mito? Recorrendo a uma diferenciação do corpo de juízes, que permite um tipo de defesa diversa à medida que a peça avança. O último juíz a intervir é uma mulher: a Jueza Cuarta. O seu interrogatório processa-se como uma verdadeira preocupação por averiguar as razões de Antígona e o contexto que determina essas razões. E isto abre espaço para que Antígona evoque a relação afectuosa entre todos os irmãos, ainda que Etéocles fosse o mais distante, por ser o mais velho, a relação afectuosa entre filhos e pais - Édipo, um rei humanizado, segundo Antígona, o melhor rei que Tebas teve (p. 115), e Jocasta, uma mulher enérgica, cuja energia se vê herdada por Antígona, e extremamente preocupada com a educação dos filhos e das filhas. A diferenciação desta Jueza Cuarta em relação aos outros juízes e a sua sintonia adivinhada com Antígona, que, de resto, vai crescendo, encontra eco na velha que constitui o Pueblo Cuatro. Temos, assim, uma convergência feminina que faz vingar a voz e a força vital da mulher nesta peça, sobre tirania, arbitrariedade, hipocrisia. Nesse aspecto a peça evolui para se enquadrar em modernas tendências da reescrita de Antígona como uma afirmação mais que feminina - feminista 9 .

O que, aparentemente, constitui uma peça num só acto, respeita o ritmo da peça sofocliana. Não há intervenções corais a separar episódios, mas quatro momentos de silêncio que, a meu ver, desempenham esse papel. Precisamente, a intervenção da Jueza Cuarta e o universo feminino e de afectos familiars revividos, que se abre no diálogo entre Antígona e a juíza, provocam uma espécie de

\footnotetext{
${ }^{8}$ Esta leitura, fundamentada e extremamente lúcida da Antígona de Sófocles é da autoria do teólogo Bultmann (1936) e determinou a compreensão da peça-

9 Rawlinson (2014) 101-123.
} 
insurreição entre o povo que, finalmente, proclama em uníssono a necessidade de quebrar silêncios na tirania, seguindo o grito da velha. Cai o silêncio, um silêncio longo, pesado, revelador, quebrado por um discurso hipócrita de Creonte, que se não contém mais, vendo o julgamento de Antígona tomar um perigoso rumo.

O rei propõe o que sabe ser impossível: que Antígona se dê como culpada e assim será absolvida por Creonte - mas sem exéquias para Polinices. A resposta final de Antígona destaca-se, pelo seu próprio tom, e distancia-se para um plano do universal. Antígona já não trata Creonte por 'tio', mas por 'rei', recuperando a eterna imagem do confronto entre as duas figuras. De si mesma fala na terceira pessoa, abrindo assim ao público, espectador do julgamento, um grande plano temporal, que vai desde Atenas aos nossos dias e se abre a futuras reescritas (p. 121):

Entonces no hay conciliación possible, rey Creonte. Antígona actúa por deberes y por principios, tú por mantener una imagen determinada. Antígona actúa como persona justa y como ciudadana, tú solo como gobernante injusto y como tirano. Antígona actua por amor a su hermano, tú por conserver el poder. Antígona jamás pactará nada contigo, rey Creonte.

Estas são as palavras que permanecem a ecoar no desfecho da peça: um julgamento em aberto, num impasse entre Antígona e Creonte. Pociña recupera a imagem do conflito inultrapassável, que remonta à leitura de Hegel e de Goethe, mas esse conflito é entre pessoas e não entre princípios simétricos. A justiça e os afectos permanecem do lado feminino; Creonte é o tirano. E o julgamento permanence em aberto ao futuro: trata-se do todo dos 'julgamentos'-releituras de Antígona, havidos e a haver - daí o futuro 'pactará' e o distanciamento de Antígona em relação a si mesma, operado pela utilização da terceira pessoa. 
Três vozes no feminino: a de Medeia, de Safo e de Antígona. As duas primeiras estão marcadas pelo signo do intimismo e da riqueza e tensão interior do coração feminino; a terceira abre-se ao espaço público, unindo família, afectos, ao sentido de justiça e acção na pólis. Constituem, assim, uma verdadeira trilogia de vozes no feminino que se completa em si mesma.

A última voz, como se disse, é a de Antígona, que ecoa, temporal/ intemporal, e se oferece a quem recolha o seu mito para o recriar, nele projectando tensões e interrogações que marcam a historicidade de quem reescreve e quem julga. É esta a força do mito, que se constitui em interpelação constante, do passado ao presente, do passado ao futuro, nas diversas formas que a comunidade vai assumindo.

\section{Bibliografia}

Brandão, J. L. (2001) "XIII Festival de Teatro de Tema Clássico 2011" Humanitas $43,842-846$.

Bultmann, R.(1967, reed. de 1936) "Polis und Hades in der Antigone des Sophokles" in H. Diller (ed.), Sophokles, Darmstadt, Wissenschaftliche Buchgesellschaft, 311-324.

Fialho, M. C. (2000), "Sobre o trágico em Antígona de Sófocles" in V. Jabouille et al. (eds.), Estudos sobre Antígona, Lisboa, Inquérito, 29-50.

Honig, B., Antigone. Interrupted (2013) Cambridge, University Press.

Martínez Martínez, J. M. (2009), “Medea en Camariñas”, Philologica Urcitana 1, 71-84.

Rawlinson, M. C. (2014), "Beyond Antigone: Ismene, Gender and the Right to Life" in T. Chanter, S. D. Kirkland (eds.), The Returns of Antigone. Interdisciplinary Essays, New York, State University Press, 101-123.

Romero Mariscal, L. (2012), "Safo en el teatro español contemporáneo: Atardecer en Mitilene de Andrés Pociña”, Humanitas 64, 203-217. 